\title{
Student Monitoring System pada J2ME menggunakan Web Service (Studi Kasus: SMK Telekomunikasi Tunas Harapan Tengaran)
}

\author{
1) De wi Pus pitas ari, ${ }^{2)}$ Hendry, ${ }^{3)}$ Ramos Somya \\ Fakultas Teknologi Informasi \\ Universitas Kristen Satya Wacana \\ J1. Diponegoro 52-60, Salatiga 50711, Indonesia \\ 1) dewii.puspitasarii@yahoo.com, ${ }^{2)}$ hendry@ @staff.uksw.edu \\ ramos.6005@gmail.com
}

\begin{abstract}
Violations of the students is often become problems at school. As truant, fighting, smoking and others. In addition to teachers, parents also have an important role to contribute and supervise their children at school. Student monitoring system is important to help parents supervise their children at school. Both in value, attendance, payment data and the violation of the student in school. To facilitate parents in accessing this system, the system was built based on J2ME. J2ME is a development environment designed to put the Java software on mobile devices. The system can run on mobile devices that support Java applications. Server is built using web-based web service. Web services allow to exchange the use of existing functions so can use the functions from one application to make an application to another on a different network. That way, parents can get information at any time without limited by the number of characters.
\end{abstract}

Keywords: Student Monitoring, J2ME, Web Service

\begin{abstract}
Abstrak
Pelanggaran siswa sering menjadi masalah di sekolah. Seperti membolos, berkelahi, merokok dan lain-lain. Selain guru, orang tua juga punya peran penting untuk turut serta mengawasi anaknya di sekolah. Sistem monitoring siswa me mbantu orang tua mengawasi anaknya di sekolah baik dalam nilai, absensi, data pembayaran maupun pelanggaran yang dilakukan siswa di sekolah. Untuk memudahkan orang tua dalam mengakses sistem ini, maka dibangun sistem yang berbasis J2ME. J2ME adalah lingkungan pengembangan yang didesain untuk meletakkan perangkat lunak Java pada perangkat selular. Sistem ini dapat berjalan pada perangkat selular yang mendukung aplikasi java. Server dibangun berbasis web dengan memanfaatkan web service. Web service memungkinkan untuk melakukan pertukaran pemakaian fungsi-fungsi yang ada sehingga bisa memakai fungsi dari aplikasi yang satu untuk membuat suatu aplikasi yang lain pada jaringan yang berbeda. Dengan begitu maka orang tua dapat memperoleh informasi kapanpun tanpa terbatas oleh ju mlah karakter.
\end{abstract}

Kata Kunci: Monitoring Siswa, J2ME, Web Service

\section{Pendahuluan}

Ketertiban siswa sering kali menjadi suatu masalah di sebuah sekolah, apalagi pada jenjang sekolah menengah atas. Banyak kenakalan siswa yang terjadi di sekolah, seperti membolos sekolah, penyelewengan uang sekolah, terlibat tawuran, dan lain-lain. Walaupun pihak sekolah mempunyai bagian kesiswaan yang bertugas untuk memberi sanksi tegas terhadap siswa yang melanggar peraturan di sekolah, serta wali kelas yang selalu memantau nilai dan sikap siswa di sekolah, namun sering kali tidak efektif dan mengalami hambatan karena tidak didukung oleh guruguru yang lainnya dan kurangnya kepedulian terhadap siswa. Oleh karena itu peran aktif dari orang tua juga sangat penting. Orang tua harus bisa ikut mengawasi segala bentuk kegiatan anaknya di sekolah. Untuk memudahkan orang tua mengawasi anaknya di sekolah, diperlukan suatu sistem monitoring yang mampu menyediakan informasi bagi orang tua mengenai absensi, nilai, data pelanggaran dan data keuangan.

Java 2 Micro Edition atau yang disebut J2ME adalah platform yang dapat berjalan pada sistem operasi Symbian. J2ME adalah lingkungan pengembangan yang didesain untuk meletakkan perangkat lunak Java pada barang elektronik beserta perangkat pendukungnya. J2ME biasa digunakan pada telepon selular, pager, personal digital assistants (PDA) dan sejenisnya [2]. 
Sekolah Menengah Kejuruan (SMK) Telekomunikasi Tunas Harapan adalah sekolah yang siswanya didominasi oleh laki-laki. Rata-rata siswanya berasal dari luar kota. Sehingga mereka harus tinggal di asrama atau kos-kosan [3]. Mereka jauh dari orang tua dan perilaku mereka tidak diawasi. Banyak pengaruh buruk dalam pergaulan yang diberikan. Daftar pelanggaran yang tercacatat juga meningkat dari tahun sebelumnya. Pertengahan tahun 2011 tercatat 67 kasus pelanggaran yang dilakukan siswa. Dan pertengahan tahun 2012 tercatat 82 pelanggaran yang dilakukan oleh siswa [4]. Bukan tidak mungkin pelanggaran ini akan terus meningkat pada akhir tahun 2012. Secara garis besar banyaknya pelanggaran yang dilakukan oleh siswa akan berpengaruh terhadap kemajuan dan prestasi belajar di sekolah [5]. Sistem monitoring yang ada di SMK Telekomunikasi Tunas Harapan saat ini masih menggunakan teknologi Short Message Service (SMS), sehingga orang tua harus berulang kali mengirimkan SMS kepada wali kelas untuk memantau anaknya di sekolah. Informasi yang di dapatkan juga terbatas oleh panjang karakter SMS. Dari hasil kuisioner yang dibagikan, didapat kesimpulan bahwa sebagian besar orang tua siswa di SMK Telekomunikasi Tunas Harapan menggunakan perangkat mobile yang mendukung teknologi Java.

Melihat permasalahan-permasalahan tersebut maka munculah keinginan untuk membangun sebuah Student Monitoring System pada J2ME menggunakan Web Service. Web service memiliki keunggulan dalam pertukaran data antara server dan klien.

\section{Tinjauan Pustaka}

Salah satu penelitian yang membahas tentang sistem monitoring adalah "Sistem Monitoring Presensi dan Akademik Siswa Berbasis SMS Gateway (Studi Kasus: SMA Persatuan Tulangan)“. Sistem monitoring ini menyediakan informasi mengenai nilai, presensi, kegiatan sekolah dan catatan dari wali kelas. Pihak sekolah akan mengirimkan SMS kepada orang tua tentang presensi hariannya. Sistem monitoring yang dibangun menggunakan SMS Gateway sebagai monitoring bagi pihak orang tua. Sedangkan sistem monitoring bagi pihak sekolah menggunakan web [6].

Penerapan web service dalam pengembangan sistem sudah cukup banyak digunakan. Pada penelitian sebelumnya yang berjudul "Perancangan Prototype Aplikasi Mobile Untuk Pengaksesan Web Service" membahas perancangan prototype aplikasi mobile menggunakan Java Micro Edition (Java ME) untuk mengakses web service. Web service yang diakses oleh aplikasi yang dirancang adalah web service pada suatu Sistem Infromasi Akademik. Web service ini mengembalikan Indeks Prestasi Semester, Indeks Prestasi Kumulatif, dan Nilai suatu Mata kuliah. Hasil pengujian terhadap prototype aplikasi menunjukkan bahwa aplikasi bekerja sesuai dengan yang diharapkan [7].

Penelitian-penelitian yang sudah ada dijadikan landasan dalam perancangan Student Monitoring System Pada J2ME Dengan Web Service ini. Perbedaan dengan penelitian sebelumnya yang dilakukan oleh Moch. Awang Putra yaitu sistem yang akan dibangun menggunakan teknologi web service yang memberikan kemudahan dalam pertukaran data. Informasi yang dihasilkan pada penelitian sebelumnya terbatas oleh panjang karakter SMS dan menghabiskan banyak biaya karena orang tua harus berkali-kali mengirim SMS untuk mendapat informasi.

\section{Student Monitoring}

Monitoring adalah proses rutin pengumpulan data dan pengukuran kemajuan atas objektif program. Memantau perubahan, yang fokus pada proses dan keluaran. Monitoring melibatkan perhitungan atas apa yang dilakukan. Monitoring melibatkan pengamatan atas kualitas dari layanan yang diberikan. Student Monitoring adalah melakukan pengawasan dan pengontrolan terhadap perkembangan akademik siswa di sekolah. Baik itu dalam proses nilai siswa, pelanggaran ataupun proses ketidakhadiran siswa dalam proses kegiatan belajar-mengajar [8].

J2ME

Java 2 Micro Edition (J2ME) adalah lingkungan pengembangan yang didesain untuk meletakkan perangkat lunak java pada barang elektronik beserta perangkat pendukungnya. Pada J2ME, jika perangkat lunak berfungsi baik pada sebuah perangkat maka belum tentu juga berfungsi baik pada perangkat yang lainnya. J2ME membawa java ke dunia informasi, komunikasi, dan 
perangkat komputasi selain perangkat komputer desktop yang biasanya lebih kecil dibandingkan perangkat komputer desktop. J2ME biasa digunakan pada telepon selular, pager, personal digital assistants (PDA) dan sejenisnya [3].

J2ME adalah bagian dari J2SE, karena itu tidak semua library yang ada pada J2SE dapat digunakan pada J2ME. Tetapi J2ME mempunyai beberapa library khusus yang tidak dimiliki J2SE. Arsitektur J2ME dapat dilihat pada Gambar 1 :

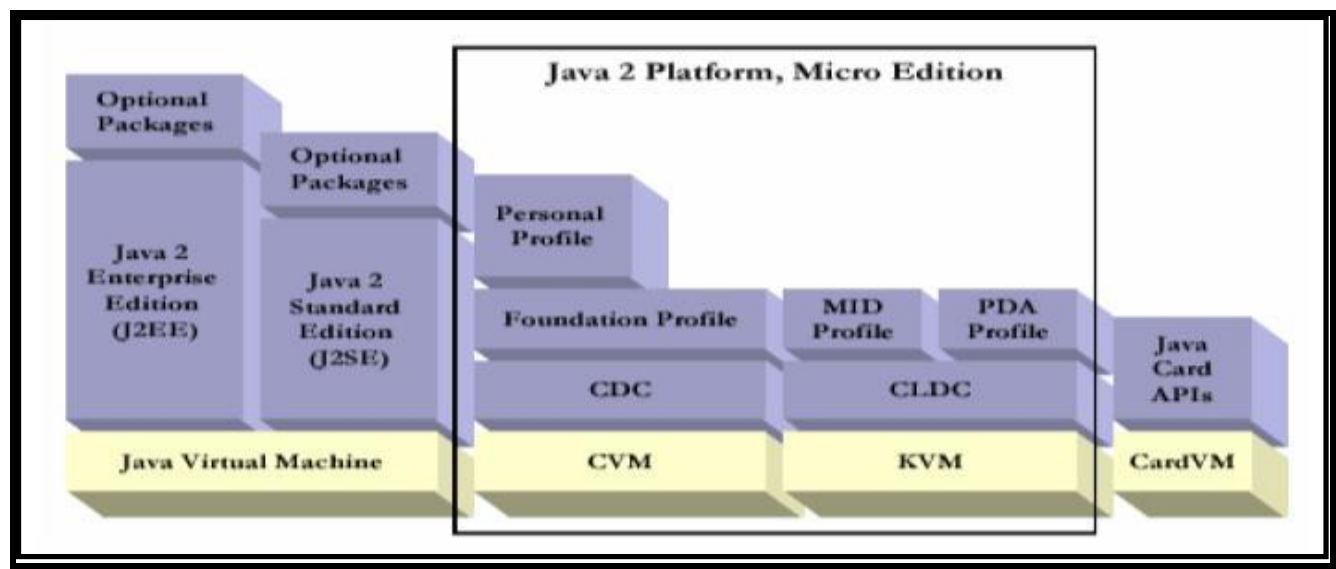

Gambar 1 Arsitektur J2ME [9]

Dari Gambar 1, J2ME mempunyai lapisan konfigurasi dan profile yang didukung oleh Java Virtual Machine (C-Virtual Machine dan K-Virtual Machine). Aplikasi yang berjalan pada sebuah perangkat yang mendukung MIDP disebut dengan MIDlet. Dengan kata lain MIDlet merupakan aplikasi dari MIDP (Mobile Information Device Profile). MIDlet berupa kelas abstrak yang merupakan sub kelas dari bentuk dasar aplikasi sehingga antarmuka antar aplikasi J2ME dan aplikasi manajemen pada perangkat dapat terbentuk [10].

\section{Web Service}

Web Service adalah sekumpulan application logic beserta object-object dan methodmethod yang dimilikinya yang terletak di suatu server yang terhubung ke internet sehingga dapat diakses menggunakan protocol HTTP dan SOAP. Tujuan dari teknologi ini adalah untuk memudahkan beberapa aplikasi atau komponennya untuk saling berhubungan dengan aplikasi la in dalam sebuah organisasi maupun diluar organisasi menggunakan standar yang tidak terikat platform dan tidak terikat akan bahasa pemrograman yang digunakan. Web service menyimpan data informasi dalam format XML, sehingga data ini dapat diakses oleh sistem lain walaupun berbeda platform, sistem operasi maupun bahasa compiler. Penggunaan Web Service juga menawarkan kelebihan dan fleksibilitas, diantaranya [11] :

- Lintas Platform

- Jembatan Penghubung Dengan Database

- Language Independent

- Mempermudah Proses Pertukaran Data

- Penggunaan Kembali Komponen Aplikasi

Web Service mempublikasikan aplikasi dalam bentuk layanan (services) yang sekali dipublikasikan di internet akan bisa ditemukan dan diakses oleh aplikasi lain di internet tidak tergantung pada platform yang digunakan. Operasi suatu web service digambarkan sebagai hubungan antara tiga peran yang berbeda yaitu Service Provider, Service Registry dan Service Requestor [12]. Hubungan ketiganya digambarkan pada Gambar 2. 


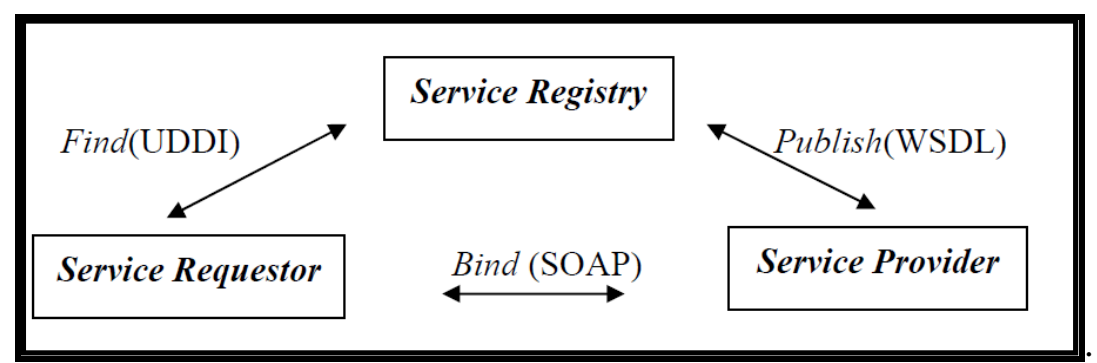

Gambar 2 Hubungan Antara Peran Dalam Web Service (Kuswandi, 2007)

- Service Provider: Berfungsi untuk menyediakan layanan/ service dan mengolah sebuah registry agar layanan-layanan tersebut dapat tersedia.

- Service Registry: Berfungsi sebagai lokasi central yang mendeskripsikan semua layanan/ service yang telah di-register.

- Service Requestor: Peminta layanan yang mencari dan menemukan layanan yang dibutuhkan serta menggunakan layanan tersebut.

\section{SOAP}

SOAP merupakan protokol yang digunakan untuk mempertukarkan data atau informasi dalam format XML. SOAP dapat dikatakan sebagai gabungan antara HTTP dengan XML karena SOAP umumnya menggunakan protocol HTTP sebagai sarana transportasi datanya dan data akan dipertukarkan ditulis dalam format XML. Karena SOAP mengunakan HTTP dan XML maka SOAP memungkinkan pihak-pihak yang mempunyai platform, sistem operasi dan perangkat lunak yang berbeda dapat saling mempertukarkan datanya [13]. Dalam J2ME, SOAP didef inis ikan dalam JSR 172. JSR 172 adalah package standar akses J2ME ke web service [14]. JSR 172 mendefinisikan API untuk Web Services.

\section{NuSoap}

NuSOAP merupakan salah satu dari sekian toolkit yang tersedia untuk programmer PHP yang ingin bekerja dengan layanan SOAP. Keunggulan yang ditawarkan oleh NuSOAP adalah karena kesederhanaan sebab justru karena sederhana dan mudah sehingga kecepatannya menjadi lebih baik [15].

\section{Metode Penelitian}

Metode pengembangan sistem yang digunakan pada penelitian ini adalah metode Prototyping. Prototyping adalah proses yang digunakan untuk membantu pengembangan perangkat lunak dalam membentuk model dari perangkat lunak yang harus dibuat [16]. Metode ini dilakukan secara bertahap, yaitu dengan mengembangkan suatu prototype yang sederhana terlebih dahulu baru kemudian dikembangkan dari waktu ke waktu sampai perangkat lunak selesai dikembangkan. Prototype merupakan bentuk dasar atau model awal dari suatu sistem atau subsistem. Tahap-tahap dalam metode Prototype ditunjukkan pada Gambar 3.

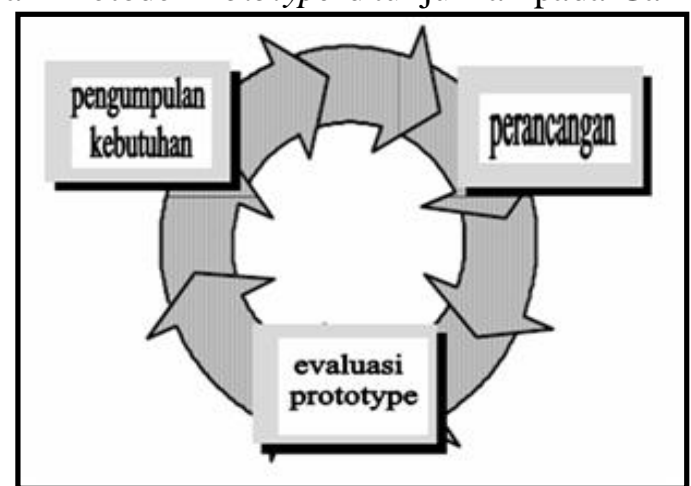

Gambar 3 Tahapan dalam Model Prototyping [16] 


\section{- Pengumpulan Kebutuhan}

Tahap ini untuk mengetahui dan menerjemahkan semua permasalahan serta kebutuhan perangkat lunak dan kebutuhan sistem yang dibangun. Analisis kebutuhan dilakukan dengan melakukan pencarian data-data serta informasi-informasi yang dibutuhkan oleh sistem. Ada empat analis is kebutuhan dalam perancangan sistem yaitu analis is kebutuhan sistem, analisis kebutuhan data, analisis kebutuhan perangkat keras dan analisis kebutuhan perangkat lunak. Dalam tahap ini dilakukan analis is terhadap kebutuhan pengguna, kebutuhan pengguna tersebut antara lain:

- Orang Tua Siswa adalah sasaran utama dari pembuatan aplikasi. Diharapkan orang tua dapat memperoleh informasi mengenai absensi, nilai, pe langgaran dan data keuangan siswa di sekolah. Orang tua harus login dahulu agar bisa mengakses aplikasi ini dengan username dan password yang sudah ditentukan dari sekolah.

- Wali Kelas dapat melihat semua data tentang siswa dan mengisi catatan-catatan yang perlu diperhatikan oleh orang tua.

- Guru Mata Pelajaran dapat mengisi nilai siswa serta mengisi absensi.

- Guru BP atau Kesiswaan dapat mengisi pelanggaran-pelanggaran yang dilakukan siswa di sekolah.

- Administrasi di Tata Usaha dapat mengisi kewajiban keuangan siswa yang harus dibayar dan jatuh tempo pembayaran.

- Admin dapat melakukan pengaturan penuh atas sistem. Seperti menambah, mengubah dan menghapus data siswa, melakukan pengaturan hak akses user, serta menambah, mengubah atau menghapus operator pengguna sistem, menambah, mengubah serta menghapus data pelanggaran.

\section{Perancangan Sistem}

Setelah melakukan pengumpulan kebutuhan, se lanjutnya yang dilakukan adalah melakukan perancangan arsitektur dan perancangan sistem. Gambar 4 menunjukkan rancangan arsitekstur untuk student monitoring system.

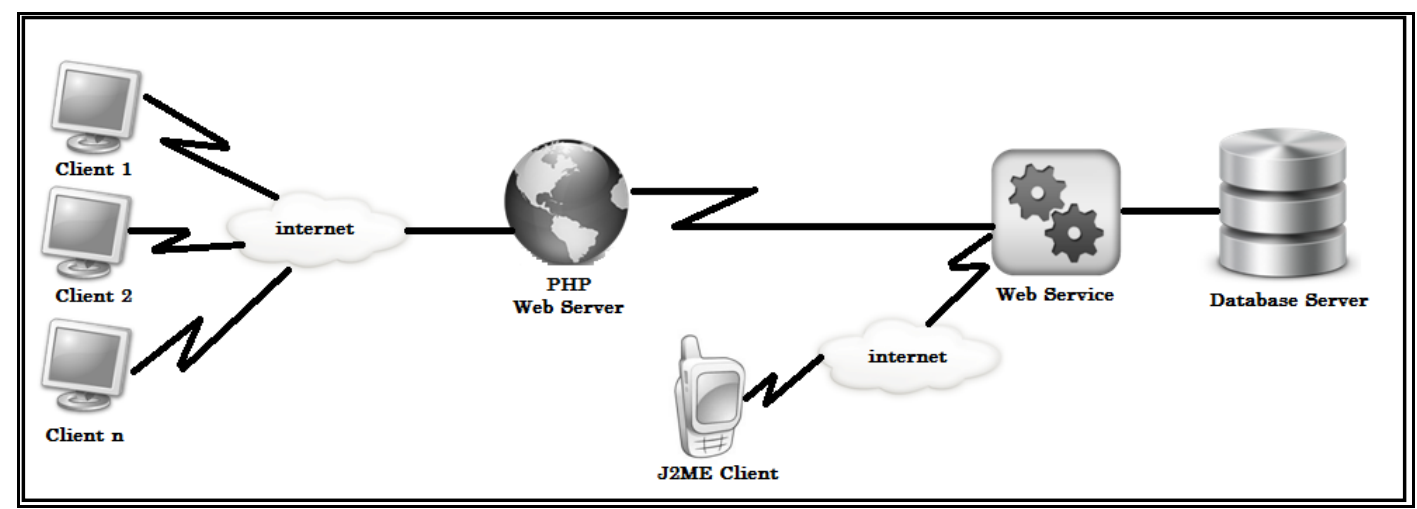

Gambar 4 Rancangan Arsitektur Student Monitoring System

Gambar 2 merupakan rancangan arsitektur student monitoring system. Terdapat tiga aplikasi yaitu web server, J2ME dan web service. Web service menghubungkan antara web server dan J2ME dengan database server.

Perancangan sistem dibuat menggunakan diagram UML. Rancangan yang ada mewakili semua aspek software yang diketahui, dan rancangan ini sebagai dasar dalam pembuatan prototype.

Use case diagram menggambarkan interaksi antara aktor-aktor dengan sistem yang dibangun serta menggambarkan fungsionalitas yang dapat diberikan sistem kepada user.Use case diagram sistem ditunjukkan pada Gambar 5. 


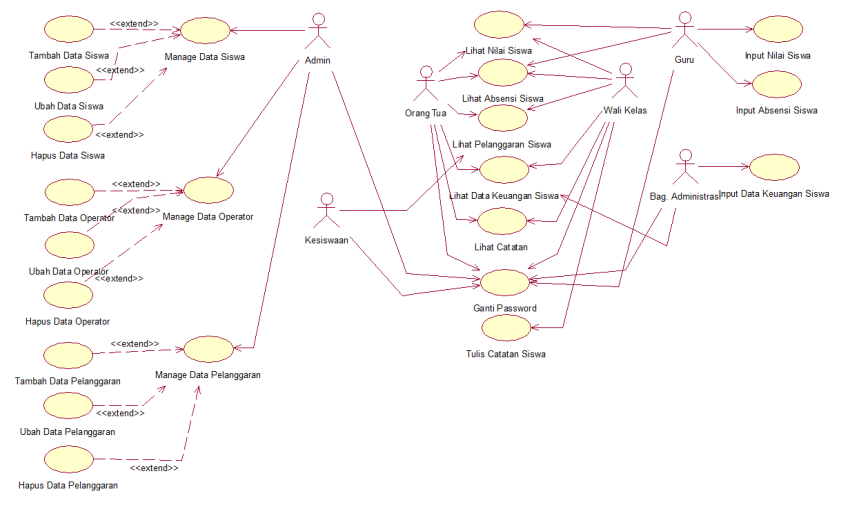

Gambar 5 Use case Diagram Student Monitoring System

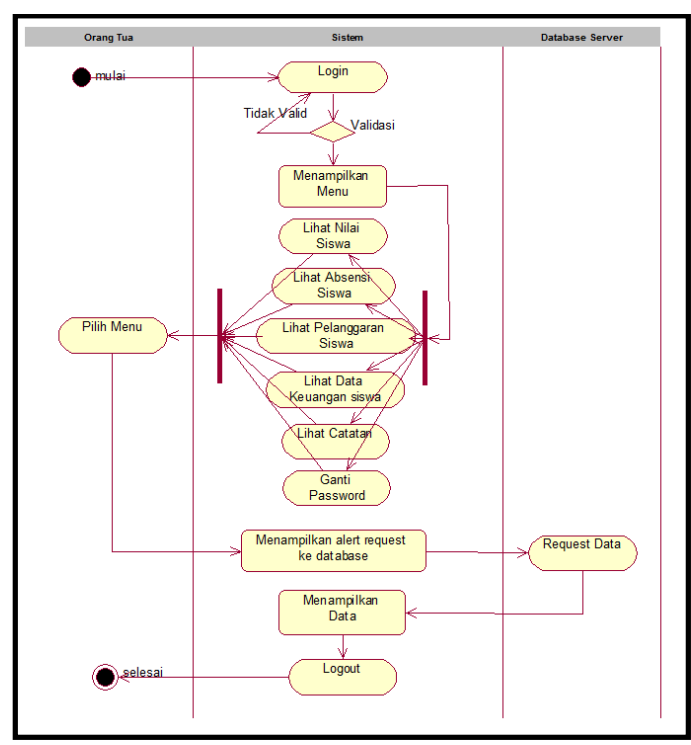

Gambar 6 Activity Diagram Orang Tua

Activity diagram menggambarkan aliran aktifitas dalam sistem yang sedang dirancang, bagaimana masing-masing alir berawal, decision yang mungkin terjadi, dan bagaimana mereka berakhir. Diagram mewakili aktivitas setiap aktor dalam menggunakan sistem. Gambar 6 merupakan activity diagram orang tua saat masuk ke sistem.

Dari Gambar 6 dapat dijelaskan, orang tua harus login dahulu sebelum masuk ke menu utama. Setelah username dan password valid, maka akan tampil menu utama. Terdapat 6 menu utama yaitu lihat nilai, lihat absensi, lihat pelanggaran, lihat data keuangan, lihat catatan dan ganti password. Setelah memilih salah satu menu, aplikasi akan menampilkan konfirmasi untuk meneruskan request ke database. Kemudian sistem akan menampilkan data.

Class diagram aplikasi mobile ditunjukkan Gambar 7.

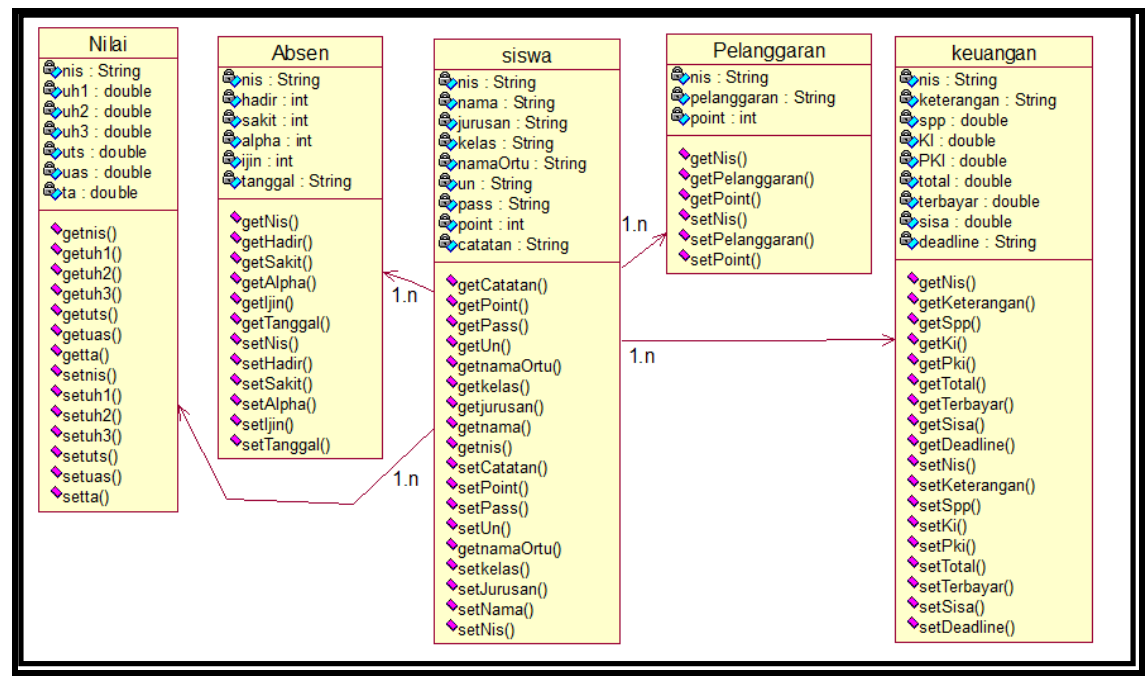

Gambar 7 Class Diagram Aplikasi Mobile

Deployment Diagram adalah Deployment/ physical diagram menggambarkan detail bagaimana komponen di-deploy dalam infrastruktur sistem, di mana komponen akan terletak (pada mesin, server atau piranti keras apa), bagaimana kemampuan jaringan pada lokasi tersebut, spesifikasi server, dan hal-hal lain yang bersifat fisikal. 


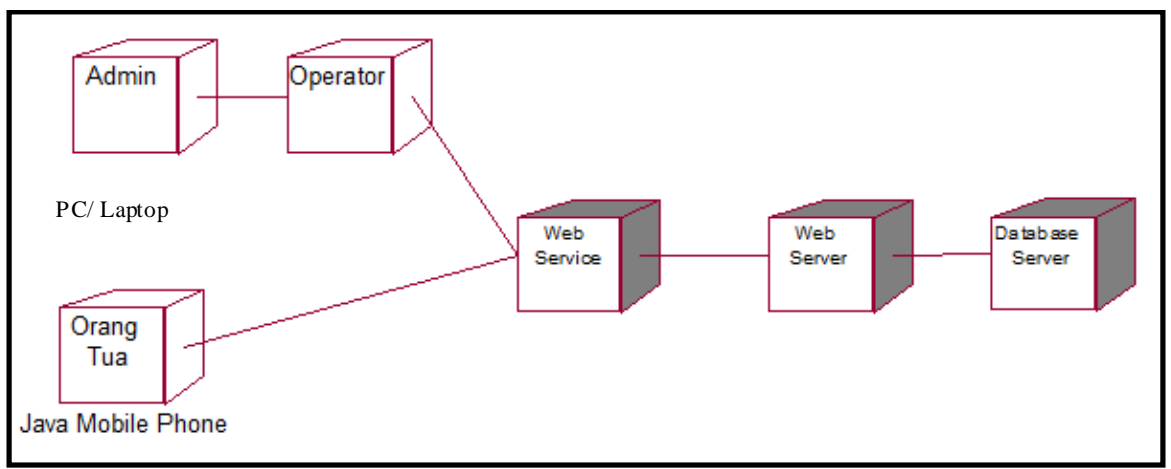

Gambar 8 Deployment Diagram Student Monitoring System

Gambar 8 merupakan deployment diagram dari sistem monitoring yang dibuat. Terdapat beberapa perangkat yang digunakan saat deployment yaitu $\mathrm{PC} /$ laptop yang digunakan untuk mengimplementasikan aplikasi web, serta perangkat Java mobile untuk mengimplementasikan aplikasi mobile. Saat orang tua merequest data maka aplikasi akan terhubung pada web server. Pertukaran data menggunakan web service sebagai jembatan penghubung.

\section{- Evaluasi Prototype}

Proses evaluasi prototyping dilakukan sebanyak dua kali pengujian dilakukan oleh user. Penjelasan setiap tahap evaluasi prototyping adalah sebagai berikut :

a. Evaluasi Tahap Pertama

Evaluasi prototype pertama dilakukan setelah perancangan awal aplikasi. Dalam tahap ini melakukan perancangan database dan desain tampilan. Hasil dari evaluasi tahap pertama antara lain: (1) Memperbaiki database sistem sesuai dengan yang dibutuhkan; (2) Memperbaiki tampilan supaya lebih menarik.

b. Evaluasi Tahap Kedua

Pada tahap kedua dilakukan penambahan proteksi sistem dan perbaikan tampilan aplikasi mobile. Proteksi yang dilakukan adalah user tidak dapat masuk ke menu utama apabila username atau password tidak sesuai. Pada halaman utama aplikasi mobile juga ditambah menu lupa password. Menu ini berfungsi untuk mengingatkan kembali password yang digunakan untuk login ke sistem.

\section{Hasil Dan Pembahasan}

Terdapat dua aplikasi untuk student monitoring system ini, yaitu aplikasi mobile dan aplikasi web. Kedua aplikasi dihubungkan oleh library nuSoap. Kode Program 1 merupakan kode program untuk koneksi menggunakan nuSoap.

Kode Program 1 Perintah Koneksi Dengan NuSoap

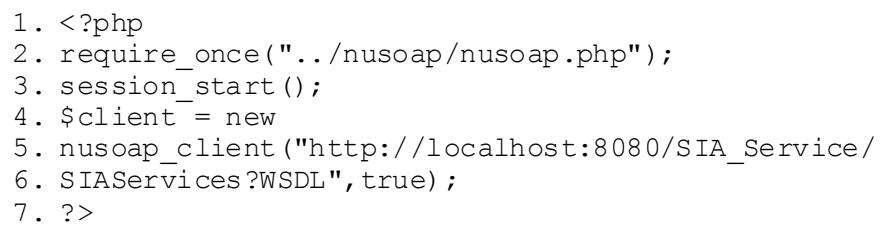

Kode Program 1 merupakan perintah koneksi menggunakan nuSoap pada aplikasi web yang melakukan request ke alamat WSDL dari service yang telah dibuat.

Berikut langkah untuk membuat koneksi antara web service dengan aplikasi mobile:

1. Klik kanan pada project mobile yang dibuat, dan pilih Java ME Web Service Client.

2. Kemudian tulis alamat WSDL ke WSDL URL. Gambar 9 merupakan tampilan ketika membuat Java ME Web Service Client. 


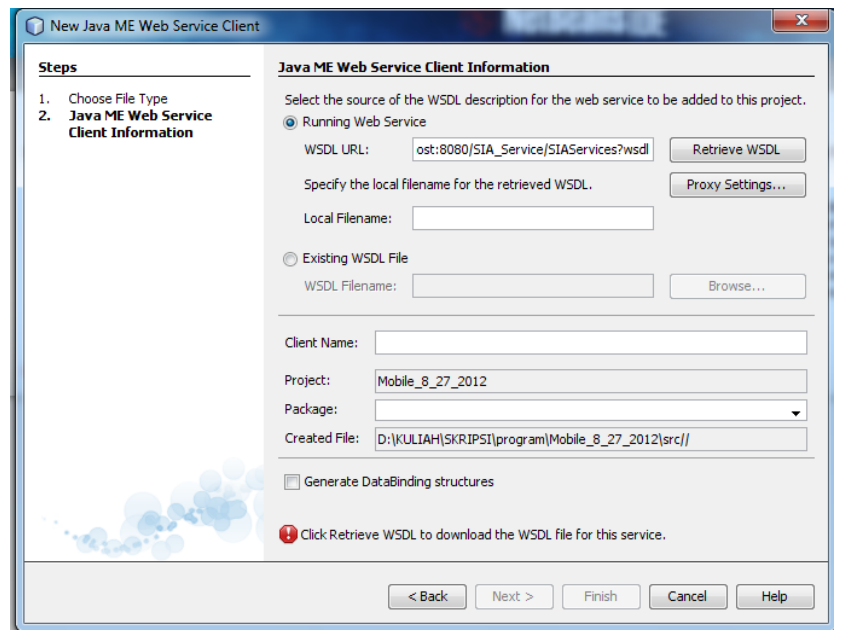

Gambar 9 Membuat Koneksi Antara Web Service Dengan Aplikasi Mobile
D Mobile_8_27_2012 - NetBeans IDE 7.0

File Edit View Navigate Source Refactor Run De
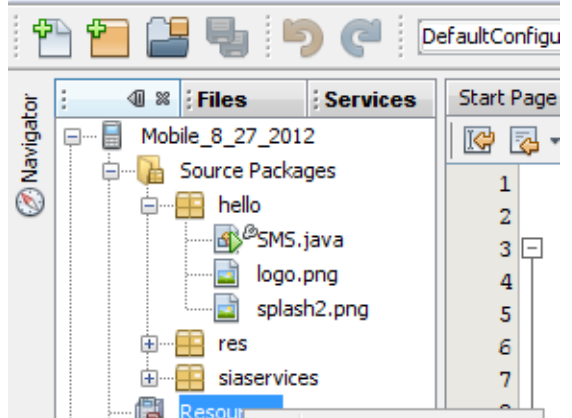

+...

$\rightarrow$ SIA Service Add Jar/Zip...

10... Web P. Add Folder...

+... B Source Add Library...

1.... Librarie

†․ㅣㄹ Py Paste

+...밀 JDK 1.0 (Derauli)

+.... 固 GlassFish Server 3.1

Gambar 10 Menambah Library JSR 172 ke Aplikasi Mobile

3. Pilih button Retrieve WSDL, kemudian pilih button Next dan Finish.

Kode Program 2 merupakan perintah untuk melakukan pemanggilan kelas SIAService_Stub pada package siaservice.

Kode Program 2 Perintah Pemanggilan Kelas SIAService_Stub pada Package siaservice

1. import siaservices.SIAServices_Stub;

Untuk mendefinisikan API dari web service digunakan library JSR 172. Berikut adalah langkah untuk menambahkan library JSR 172 ke aplikasi mobile:

1. Pilih Resources kemudian klik kanan dan pilih Add Jar/ Zip. Gambar 10 merupakan tampilan ketika menambah library JSR 172.

2. Kemudian pilih lokasi dis impannya library JSR 172 dan pilih open.

Kode Program 3 merupakan perintah untuk melakukan pemanggilan library JSR 172.

Kode Program 3 Perintah Pemanggilan Library JSR 172

1. import java.rmi.RemoteException;

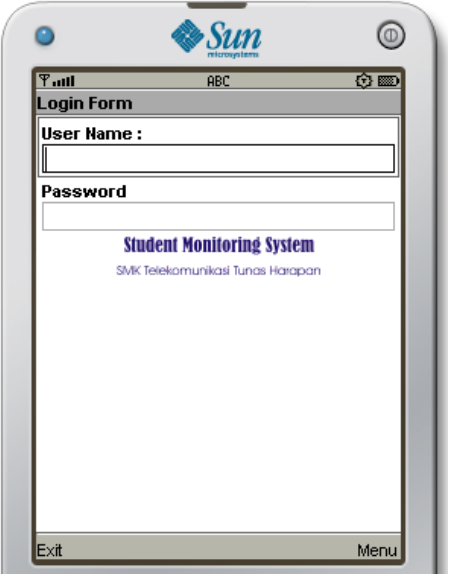

Gambar 11 Halaman Login Pada Aplikasi Mobile

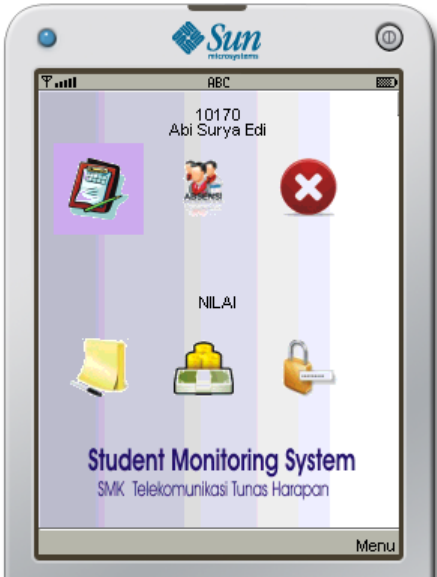

Gambar 12 Halaman Menu Utama 


\section{Antarmuka Aplikasi Client}

Tampilan awal dari aplikasi mobile adalah spashscreen. Setelah beberapa saat akan muncul form login. Orang tua harus login untuk masuk ke menu utama. Pada form login terdapat pilihan login dan lupa password. Gambar 11 merupakan tampilan form login pada aplikasi mobile.

Kode program 4 merupakan kode dari service login pada aplikasi mobile.

Kode Program 4 Perintah Untuk Penanganan Service Login Pada Aplikasi Mobile

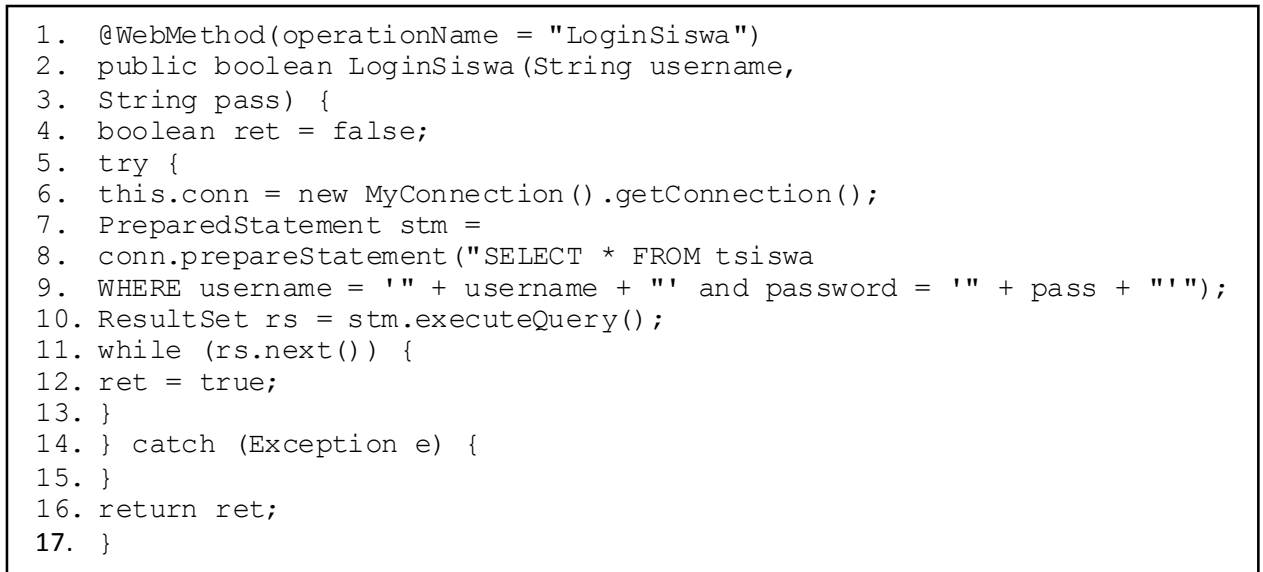

Kode program 5 merupakan kode program untuk login pada aplikasi mobile. Pertama dipanggil service login orang tua yang sudah dibuat, apabila username dan password benar maka aplikasi akan menampilkan menu utama. Apabila username atau password salah makan akan ditampilkan pesan gagal login.

Kode Program 5 Perintah Untuk Login Pada Aplikasi Mobile.

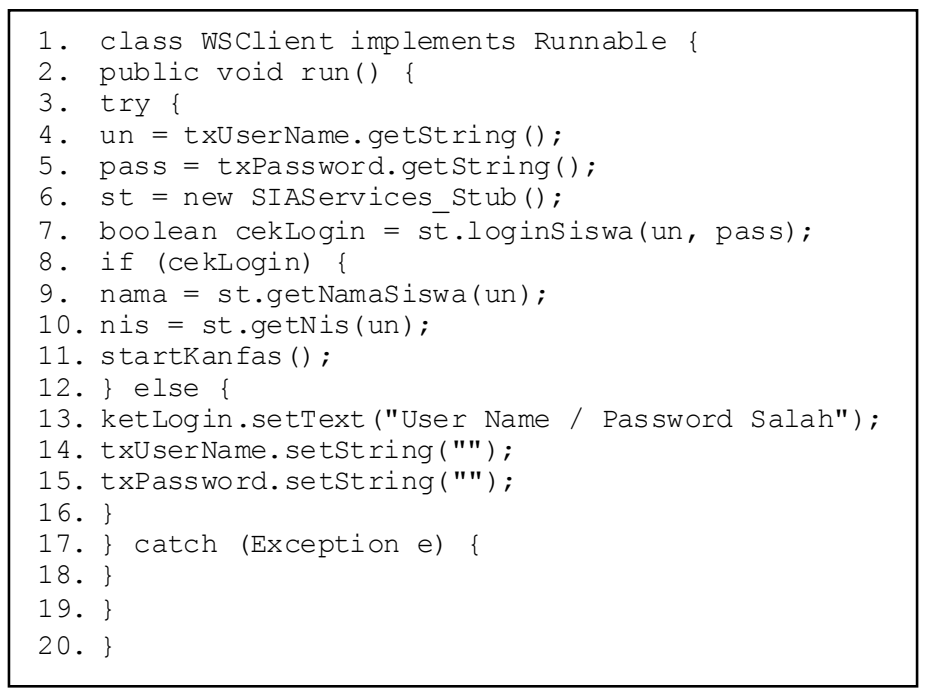

Setelah berhasil login makan akan muncul menu utama. Terdapat 6 menu utama yaitu nilai, absensi, pe langgaran, catatan, keuangan dan ganti password. Orang tua dapat memilih menu sesuai informasi yang ingin mereka dapatkan. Gambar 12 merupakan tampilan menu utama pada aplikasi mobile.

\section{- Antarmuka Aplikasi Web}

Tampilan awal dari aplikasi web adalah halaman login. Seperti pada perancangan, pada implementasi juga diterapkan demikian. Yaitu terdapat 5 pilihan login sesuai hak akses yang dimiliki setiap operator. Tampilan utama pada aplikasi web dapat ditunjukkan oleh Gambar 13. 


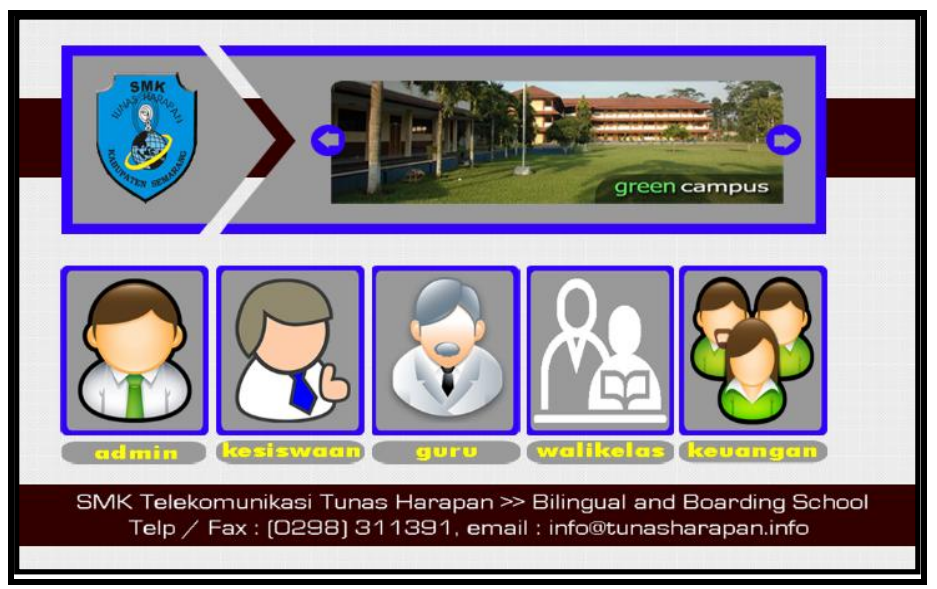

Gambar 13 Halaman Login Pada Aplikasi Web

Kode program 6 merupakan kode program dari service login pada halaman web.

Kode Program 6 Perintah Untuk Penanganan Service Login Pada Halaman Web

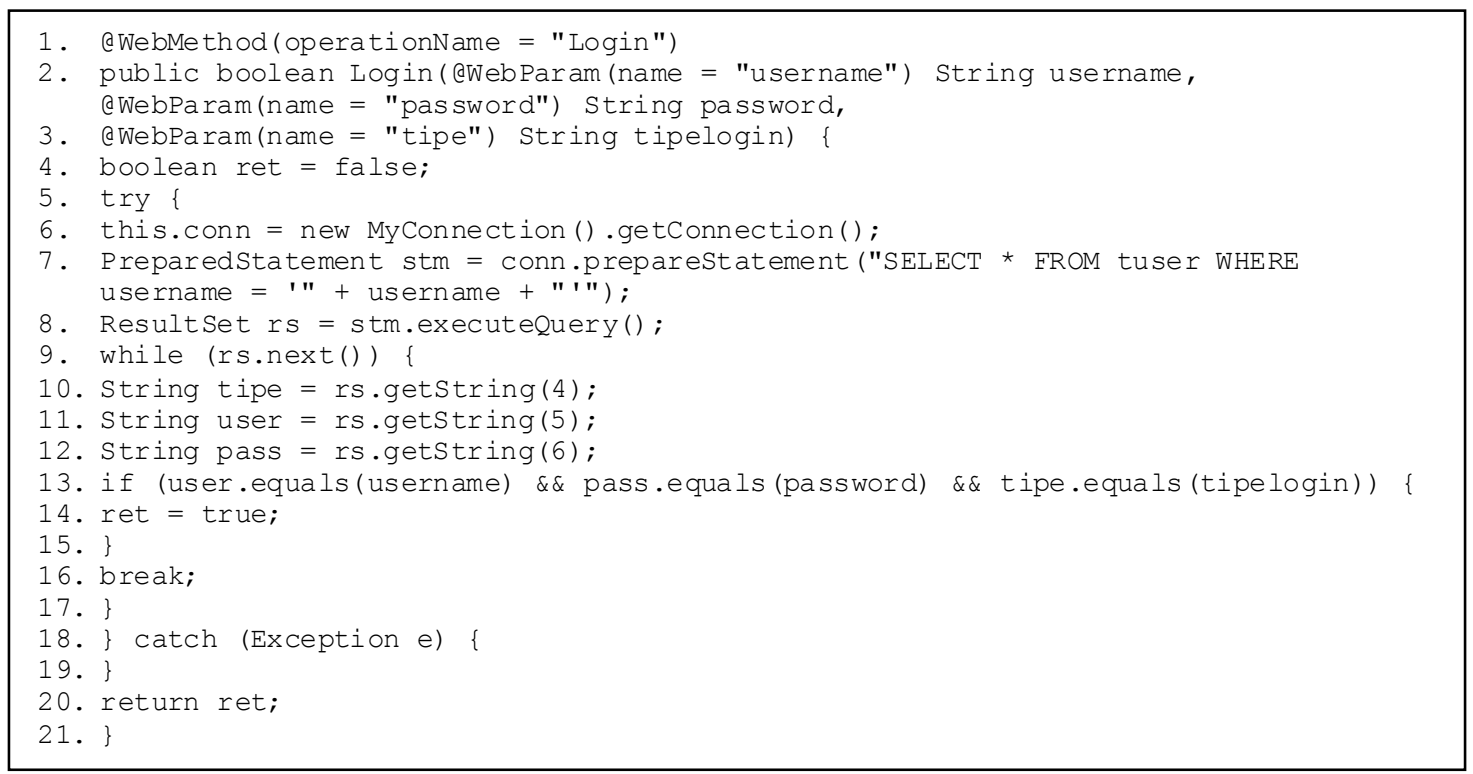

Kode program 7 merupakan kode program untuk login pada halaman web. Petama dipanggil service login yang sudah dibuat, apabila username dan password benar maka sistem akan melakukan cek terhadap hak akses yang digunakan. Apabila hak akses adalah admin maka akan ditampilkan halaman admin. Apabila hak akses adalah guru maka akan ditampilkan halaman guru. Apabila hak akses adalah kesiswaan maka akan ditampilkan halaman kesiswaan. Apabila hak akses adalah wali kelas maka akan ditampilkan halaman wali kelas. Apabila hak akses adalah administrasi maka akan ditampilkan halaman administrasi. Apabila username atau password salah makan akan ditampilkan pesan gagal login. 
Kode Program 7 Perintah Untuk Login Pada Halaman Web.

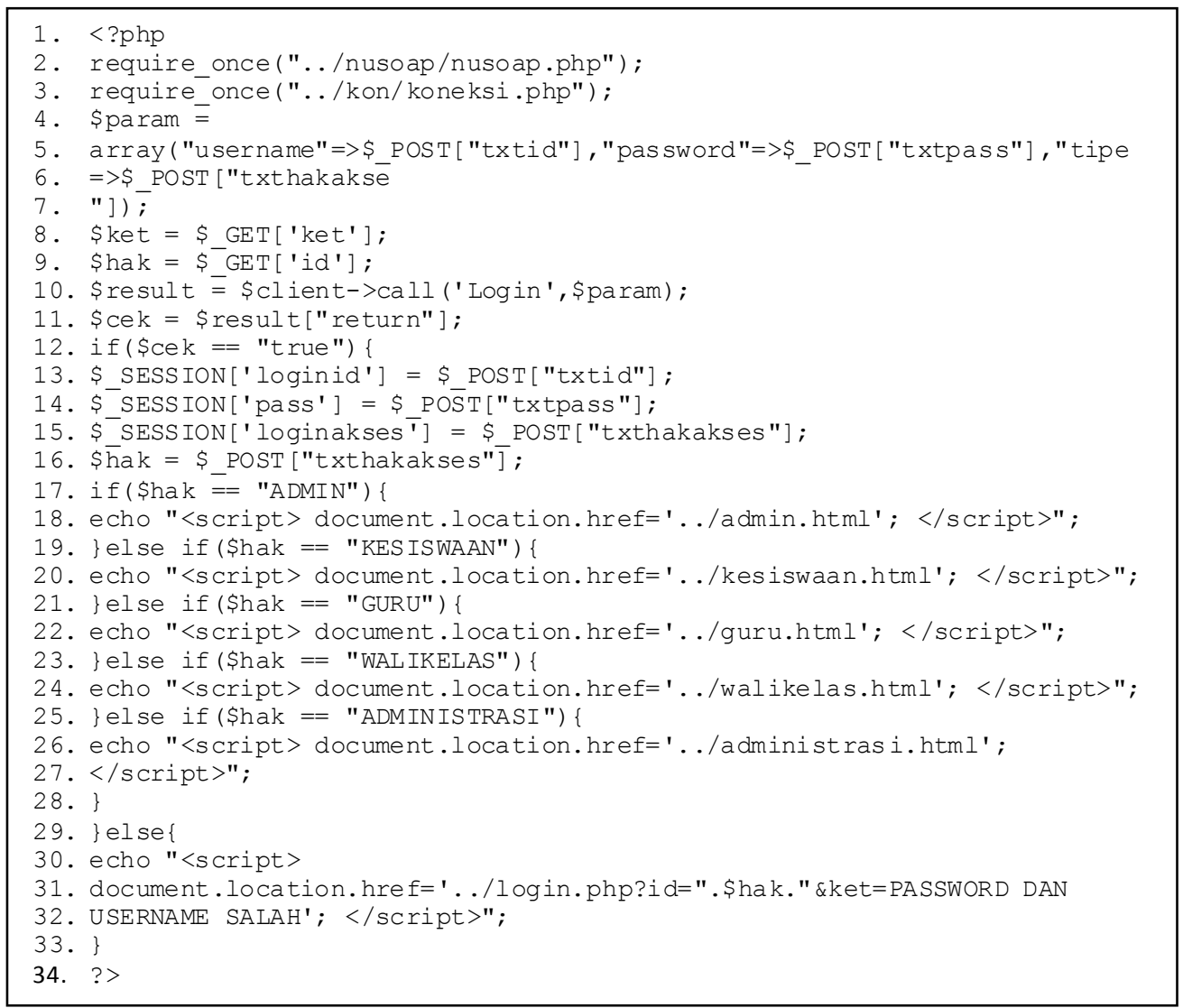

\section{- Pengujian Sistem}

Pengujian ini berfungsi untuk melihat sejauh mana aplikasi ini dapat berjalan dan untuk menemukan kesalahan yang mungkin terjadi. Tahap ini merupakan tahapan untuk menemukan beberapa kekurangan yang ada dalam sistem. Pengujian aplikasi ini seperti yang dijelaskan pada tahap sebelumnya, menggunakan dua teknik pengujian, yaitu:

\section{a. Pengujian Alfa}

Pengujian alfa merupakan pengujian aplikasi yang dilakukan oleh pembuat ataupun orangorang yang terlibat di dalamnya. Pengujian alfa hanya untuk sirkulasi internal dan masalah (error) atau ketidaklengkapan yang terdapat dalam aplikasi dapat diduga sebelumnya [13]. Pengujian sistem ini menggunakan metode blackbox. Metode ujicoba blackbox memfokuskan pada keperluan fungsional dari software. Karna itu ujicoba blackbox memungkinkan pengembang software untuk membuat himpunan kondisi input yang akan melatih seluruh syarat-syarat fungsional suatu program.

\section{- Pengujian Aplikasi Mobile}

Pengujian login yaitu untuk mengecek apakah fungsional dari form login telah berjalan dengan baik atau belum. Dari pengujian yang dilakukan didapatkan kesimpulan bahwa form login pada aplikasi mobile telah berfungsi dengan baik. Tabel 1 merupakan pengujian login untuk aplikasi mobile.

Tabel 1 Pengujian Black Box Untuk Form Login Aplikasi Mobile

\begin{tabular}{|c|c|c|c|}
\hline Aktivitas & Input & Output & $\begin{array}{c}\text { Status } \\
\text { Pengujian }\end{array}$ \\
\hline Login & $\begin{array}{l}\text { Username dan } \\
\text { password }\end{array}$ & $\begin{array}{l}\text { a. Jika berhasil maka masuk ke menu utama } \\
\text { b. Jika password salah maka muncul peringatan } \\
\text { password salah }\end{array}$ & Valid \\
\hline
\end{tabular}


Pengujian menampilkan data yaitu untuk mengecek apakah fungsional dari form menampilkan data telah berjalan dengan baik atau belum. Dari pengujian yang dilakukan didapatkan kesimpulan bahwa form menampilkan data pada aplikasi mobile telah berfungsi dengan baik. Tabel 2 merupakan pengujian untuk menampilkan data.

Tabel 2 Pengujian Black Box Untuk Menampilkan Data

\begin{tabular}{|c|c|c|c|}
\hline Aktivitas & Input & Output & $\begin{array}{c}\text { Status } \\
\text { Pengujian }\end{array}$ \\
\hline $\begin{array}{l}\text { Menampilkan data nilai, absensi, } \\
\text { pelanggaran, catatan dan keuangan }\end{array}$ & - & $\begin{array}{l}\text { a. Jika terdapat data, maka data akan } \\
\text { tampil } \\
\text { b. Jika tidak ada datanya maka akan } \\
\text { muncul peringatan tidak ada data }\end{array}$ & Valid \\
\hline
\end{tabular}

Pengujian logout yaitu untuk mengecek apakah fungsional dari form logout telah berjalan dengan baik atau belum. Dari pengujian yang dilakukan didapatkan kesimpulan bahwa form logout pada aplikasi mobile telah berfungsi dengan baik. Tabel 3 merupakan pengujian logout untuk aplikasi mobile.

Tabel 3 Pengujian Black Box Untuk Form Logout

\begin{tabular}{lll}
\hline Aktivitas & \multicolumn{1}{c}{ Output } & $\begin{array}{c}\text { Status } \\
\text { Pengujian }\end{array}$ \\
\hline Logout & - & $\begin{array}{l}\text { a. Jika berhasil maka akan kembali ke tampilan menu } \\
\text { login. } \\
\end{array}$ \\
& $\begin{array}{l}\text { b. Jika tidak berhasil maka akan tetap pada form menu } \\
\text { utama }\end{array}$ & \\
\hline
\end{tabular}

\section{- Pengujian Aplikasi Web}

Pengujian login yaitu untuk mengecek apakah fungsional dari form login telah berjalan dengan baik atau belum. Dari pengujian yang dilakukan didapatkan kesimpulan bahwa form login pada aplikasi web telah berfungsi dengan baik. Tabel 4 merupakan pengujian login untuk aplikasi web.

Tabel 4 Pengujian Black Box Untuk Form Login Aplikasi Web

\begin{tabular}{|c|c|c|c|}
\hline Aktivitas & Input & Output & $\begin{array}{c}\text { Status } \\
\text { Pengujian }\end{array}$ \\
\hline $\begin{array}{l}\text { Login Admin, Kesiswaan, Guru, } \\
\text { Wali Kelas, Administrasi }\end{array}$ & $\begin{array}{l}\text { Username dan } \\
\text { password }\end{array}$ & $\begin{array}{l}\text { a. Jika berhasil maka masuk ke } \\
\text { menu utama } \\
\text { b. Jika password salah maka } \\
\text { muncul peringatan password } \\
\text { salah }\end{array}$ & Valid \\
\hline
\end{tabular}

Pengujian menambah data yaitu untuk mengecek apakah fungsional dari form menambah data telah berjalan dengan baik atau belum. Dari pengujian yang dilakukan didapatkan kesimpulan bahwa form menambah data pada aplikasi web telah berfungsi dengan baik. Tabel 5 merupakan pengujian menambah data untuk aplikasi web.

Tabel 5 Pengujian Black Box Untuk Form Login Menambah Data

\begin{tabular}{lcc} 
Aktivitas & Output & $\begin{array}{c}\text { Status } \\
\text { Pengujian }\end{array}$ \\
\hline
\end{tabular}




\begin{tabular}{|c|c|c|c|}
\hline $\begin{array}{l}\text { Admin menambah data } \\
\text { operator, data siswa, } \\
\text { data pelanggaran }\end{array}$ & $\begin{array}{llll}\text { Data yang akan di } \\
\text { input }\end{array}$ & $\begin{array}{l}\text { a. Jika berhasil maka data akan muncul } \\
\text { pada tabel } \\
\text { b. Jika gagal maka akan tetap pada form } \\
\text { tambah data dan form menjadi kosong }\end{array}$ & Valid \\
\hline $\begin{array}{l}\text { Guru menambah data } \\
\text { nilai, data absensi }\end{array}$ & $\begin{array}{l}\text { Data yang akan di } \\
\text { input }\end{array}$ & $\begin{array}{l}\text { c. Jika berhasil maka data akan muncul } \\
\text { pada tabel } \\
\text { a. Jika gagal maka akan tetap pada form } \\
\text { tambah data dan form menjadi kosong }\end{array}$ & Valid \\
\hline $\begin{array}{l}\text { Kesiswaan menambah } \\
\text { data pelanggaran }\end{array}$ & $\begin{array}{l}\text { Memasukkan } \\
\text { pelanggaran }\end{array}$ & $\begin{array}{l}\text { a. Jika berhasil maka akan tampil tabel } \\
\text { data pelanggaran dan akumu lasi point } \\
\text { akan muncul sesuai dengan } \\
\text { pelanggaran yang telah dilakukan } \\
\text { b. Jika gagal maka akan tetap pada form } \\
\text { tambah data dan form menjadi kosong }\end{array}$ & Valid \\
\hline $\begin{array}{l}\text { Wali Kelas menambah } \\
\text { data catatan }\end{array}$ & Memasukkan catatan & $\begin{array}{l}\text { a. Jika berhasil maka akan tampil tabel } \\
\text { data catatan } \\
\text { b. Jika gagal maka akan tetap pada form } \\
\text { tambah data dan form menjadi kosong }\end{array}$ & Valid \\
\hline $\begin{array}{l}\text { Admin is trasi } \\
\text { menambah } \\
\text { keuangan }\end{array}$ & $\begin{array}{l}\text { Memasukkan data } \\
\text { keuangan dan batas } \\
\text { waktu pembayaran }\end{array}$ & $\begin{array}{l}\text { a. Jika berhasil maka akan tampil tabel } \\
\text { data keuangan dan keterangan lunas/ } \\
\text { belum lunas } \\
\text { b. Jika gagal maka akan tetap pada form } \\
\text { tambah data dan form menjadi kosong }\end{array}$ & Valid \\
\hline
\end{tabular}

Berdasarkan pengujian yang dilakukan didapatkan hasil bahwa aplikasi ini sudah berjalan secara fungsional dan menge luarkan informasi sesuai dengan yang diharapkan

\section{b. Pengujian Beta}

Pengujian beta dilakukan dengan menyebar kuisioner kepada pengguna aplikasi, yaitu orang tua siswa sebagai pengguna aplikasi. Pengujian ini digunakan untuk mengetahui sejauh mana aplikasi ini berfungsi dengan baik. Kuisioner dibagi sejumlah 99 kepada orang tua atau wali murid. Dalam penafsiran data digunakan metode penafsiran data [17]. Tabel 6 menunjukkan penafsiran data menggunakan dua angka di be lakang koma.

Tabel 6 Tabel Penafsiran Persentase

\begin{tabular}{ll}
\hline Juml ah Persentase & Keterangan \\
\hline $0,00 \%$ & Tidak ada \\
$0,01 \%-24,99 \%$ & Sebagian kecil \\
$25 \%-49,99 \%$ & Hampir setengah \\
$50 \%$ & Setengahnya \\
$50,01 \%-74,99 \%$ & Sebagian besar \\
$75 \%-99,99 \%$ & Pada umu mnya \\
$100 \%$ & Seluruhnya \\
\hline
\end{tabular}

Dari hasil pengisian kuisioner nomor 1 maka diperoleh hasil bahwa sebanyak 46 responden atau sebesar 46,46\% menjawab "sangat mudah". Berarti hampir setengah responden menyatakan bahwa aplikasi sangat mudah digunakan. 42 responden atau sebesar 42,42\% menjawab "mudah". 
Berarti hampir setengah responden menyatakan bahwa aplikasi mudah digunakan. 9 responden atau sebesar 9,10\% menjawab "cukup mudah". Berarti sebagian kecil responden menyatakan bahwa aplikasi cukup mudah digunakan. Dan 2 responden atau sebesar 2,02\% menjawab "sulit". Berarti sebagian kecil responden menyatakan bahwa aplikasi sulit digunakan.

Dari hasil pengisian kuisioner nomor 2 maka diperoleh hasil bahwa sebanyak 81 responden atau sebesar $81,82 \%$ menjawab "sangat membantu". Berarti pada umumnya responden menyatakan bahwa aplikasi sangat membantu dalam proses monitoring siswa. 13 responden atau sebesar $13,13 \%$ menjawab "membantu". Berarti sebagian kecil responden menyatakan bahwa aplikasi membantu dalam proses monitoring siswa. 5 responden atau sebesar 5,05\% menjawab "cukup membantu". Berarti sebagian kecil responden menyatakan bahwa aplikasi cukup membantu dalam proses monitoring siswa. Dan tidak ada responden yang menyatakan bahwa aplikasi tidak membantu dalam proses monitoring.

Dari hasil pengisian kuisioner nomor 3 maka diperoleh hasil bahwa sebanyak 84 responden atau sebesar 84,85\% menjawab "ya". Berarti pada umumnya responden menyatakan bahwa aplikasi ini lebih fleksibel daripada sistem monitoring yang ada sebelumnya. 15 responden atau sebesar 15,15\% menjawab "tidak". Berarti sebagian kecil responden menyatakan bahwa aplikasi ini tidak lebih fleksibel daripada sistem monitoring yang ada sebelumnya.

Dari hasil pengisian kuisioner nomor 4 bahwa sebanyak 84 responden atau sebesar $84,85 \%$ menjawab "ya". Berarti pada umumnya responden setuju jika sistem monitoring yang ada saat ini diganti dengan aplikasi ini. Dan sebanyak 15 responden atau sebesar 15,15\% menjawab "tidak". Berarti sebagian kecil responden tidak setuju jika sistem monitoring yang ada saat ini diganti dengan aplikasi ini.

\section{Kesimpulan}

Berdasarkan hasil penelitian dan pembahasan maka dapat diambil kesimpulan bahwa student monitoring system ini dapat diimplementasikan dengan baik dalam bentuk aplikasi J2ME pada perangkat mobile yang menyediakan informasi bagi orang tua mengenai nilai, absensi, pelanggaran dan data keuangan siswa. Library NuSOAP digunakan untuk mengirim dan menerima pesan SOAP. NuSOAP menyediakan berbagai fungsi server maupun client yang diimplementasikan dalam PHP. Untuk akses J2ME ke web service digunakan library JSR 172 yang mendefinisikan web service API yaitu fungsi-fungsi dasar yang digunakan dalam web service client.

\section{Daftar Pus taka/Pustaka Acuan}

[1] http://www.asiamediajournal.com/pressrelease.php?id=3756. (diakses tanggal 24 Juli 2012)

[2] Deni, Adam Nur. 2011. Pengembangan Aplikasi Chat Bluetooth Pada Mobile Phone Dengan $J 2 M E$. Universitas Mercu Buana.

[3] Data SMK Telekomunikasi Tunas Harapan. 2011.

[4] Arsip Kesiswaan. 2012.

[5] Ramadhan, Tarmizi. 2008. Hubungan Pelanggaran dan Prestasi Belajar Siswa di Sekolah.

[6] Putra, Moch Awang. 2011. Sistem Monitoring Presensi dan Akademik Siswa Berbasis SMS Gateway (Studi Kasus: SMA Persatuan Tulangan). Politeknik Telkom Bandung.

[7] Wellem, Theophilus. 2009. Perancangan Prototype Aplikasi Mobile Untuk Pengaksesan Web Service. Salatiga: UKSW. 